\title{
Composição de aminoácidos em gerações precoces de feijão obtidas a partir de cruzamentos controlados com parental de alto teor de cisteína
}

\author{
Amino acid composition in common bean early generations developed from cross with high \\ cysteine content parental
}

\author{
Nerinéia Dalfollo Ribeiro ${ }^{{ }^{*}}$ Patrícia Medianeira Grigoletto Londero ${ }^{\text {II }}$ Alberto Cargnelutti Filho ${ }^{\mathrm{I}}$ \\ Nerison Luís Poersch" Sandra Maria Maziero"II
}

\section{RESUMO}

Os objetivos deste trabalho foram avaliar a composição de aminoácidos em gerações precoces de feijão, obtidas a partir de cruzamentos controlados com genitor de alto teor de cisteína, e identificar plantas com alto teor de cisteína nos grãos. A partir do cruzamento entre 'TPS Nobre' $x$ 'Minuano', foram obtidas as gerações $F_{1}, F_{1}$ recíproco, $F_{2}, F_{2}$ recíproco, retrocruzamento 1 e retrocruzamento 2 . Os aminoácidos foram determinados por cromatografia líquida de alta performance (HPLC) e os dados obtidos foram submetidos à análise de variância e de variáveis canônicas. Os aminoácidos - cisteína, prolina, tirosina, arginina, isoleucina e histidina - apresentaram variabilidade genética entre os genitores e as gerações obtidas. Os teores de aminoácidos essenciais e não-essenciais observados nos genitores e nas gerações $F_{1}$ e $F_{1}$ recíproco foram adequados para uso na alimentação. As demais gerações apresentaram deficiência em aminoácidos sulfurados. As duas primeiras variáveis canônicas explicaram 96,43\% da variação total dos genótipos $e$ dois grupos foram formados. Nenhuma planta da geração $F_{2}$ é passível de seleção pelo programa de melhoramento para o desenvolvimento de populações segregantes de feijão com alto teor de cisteína nos grãos.

Palavras-chave: qualidade protéica, aminoácidos sulfurados, variabilidade genética, variáveis canônicas.

\section{ABSTRACT}

The objective of this research was to determine the amino acid composition of early generations in common bean developed from controlled crossings with high cysteine content parental and to identify plants with high cysteine content. 'TPS Nobre' $x$ 'Minuano' were crossed and the $F_{1}, F_{1}$ reciprocal,
$F_{2}, F_{2}$ reciprocal, backcross 1 e backcross 2 generations were obtained. The amino acid contents were determinated by liquid chromatography of high performance (HPLC) and the data were submitted to analysis of variance and cannonical variables. The cysteine, proline, tyrosine, arginine, isoleucine and histidine contents showed genetic variability between the parents and the generations. The essential and nonessential amino acids contents obtained from the parents, $F_{1}$ and $F_{1}$ reciprocal generations were appropriate to be consumed. Other generations showed deficiency of the sulfur amino acids. The two first cannonical variables explained $96.43 \%$ of the total variation of the genotypes and two groups were formed. None of the plants of the $F_{2}$ generation is able to be selected by program of improvement to the development of segregating populations of common bean with high cysteine content.

Key words: protein quality, sulfur amino acids, genetic variability, cannonical variables.

\section{INTRODUÇÃO}

O valor nutritivo de uma proteína está estreitamente relacionado à proporção de aminoácidos que a compõem (MOLINA et al., 2001). A metionina é um aminoácido essencial que deverá ser fornecido nas dietas, pois sua síntese no organismo é inadequada para satisfazer as necessidades metabólicas (LAJOLO \& TIRAPEGUI, 1998). Por sua vez, a cisteína é considerada um aminoácido parcialmente essencial em determinadas condições clínicas, como em crianças prematuras.

'Departamento de Fitotecnia, Centro de Ciências Rurais (CCR), Universidade Federal de Santa Maria (UFSM), 97105-900, Santa

Maria, RS, Brasil. E-mail: neiadr@smail.ufsm.br.*Autor para correspondência.

"Programa de Pós-graduação em Agronomia (PPGA), UFSM, Santa Maria, RS, Brasil.

${ }^{\text {IIC} C u r s o ~ d e ~ A g r o n o m i a, ~ C C R, ~ U F S M, ~ S a n t a ~ M a r i a, ~ R S, ~ B r a s i l . ~}$ 
Quando os teores de aminoácidos essenciais e não-essenciais são adequados para suprir os requerimentos nutricionais, a proteína é considerada de boa qualidade (MORALES DE LEON et al., 2005). Nesse sentido, a Food and Agriculture Organization (FAO) estabeleceu os padrões para os aminoácidos em alimentos (FAO, 1998), considerando as necessidades diárias de um indivíduo adulto. De acordo com o critério adotado pela FAO, se o somatório metionina + cisteína for superior a $1,7 \mathrm{~g}$ por $16 \mathrm{~g} \mathrm{~N}$ da MS, a proteína dispõe de quantidades suficientes de aminoácidos sulfurados e será adequada para uso na alimentação.

Como o feijão (Phaseolus vulgaris L.) é deficiente em aminoácidos sulfurados (metionina e cisteína), apesar de apresentar em sua constituição todos os aminoácidos essenciais, sua proteína tem sido considerada de baixo valor biológico (ANTUNES et al., 1995; FONSECA MARQUES \& BORA, 2000; GUZMÁN-MALDONADO et al., 2000; PIRES et al., 2006). Por isso, a metionina e a cisteína deverão ser suplementadas na alimentação com a utilização de cereais para que sejam obtidos teores de aminoácidos adequados para suprir as necessidades diárias do organismo humano.

Assim, é importante avaliar a composição de aminoácidos em feijão, pois RIBEIRO et al. (2007) observaram que algumas cultivares de feijão, disponíveis para o cultivo no Brasil, apresentaram teores de aminoácidos sulfurados superiores ao padrão considerado pela FAO. Além disso, diferenças genéticas têm sido constatadas para os teores de metionina e de cisteína no germoplasma de feijão cultivado em vários países (ANTUNES et al., 1995; GUZMÁN-MALDONADO et al., 2000; RIBEIRO et al., 2007). Por isso, a identificação de cultivares de feijão com teores de aminoácidos adequados para uso na alimentação poderá contribuir para a manutenção do estado de saúde e para a prevenção de várias doenças, pois vários efeitos benéficos ao organismo têm sido relacionados aos teores de aminoácidos (COSTA, 2003).

Gerações precoces de feijão, com alto teor de metionina nos grãos, foram obtidas a partir de cruzamentos controlados com genitor de alto teor de metionina (KELLY \& BLISS, 1975). No entanto, para a cisteína, nenhum trabalho de estudo genético foi encontrado. Como a cisteína é o aminoácido parcialmente essencial encontrado em menor quantidade no feijão (ABD EL-SAMEI \& LÁSZTITY, 1984; ANTUNES et al., 1995; RIBEIRO et al., 2007), o seu aumento, por melhoramento genético, é desejável para que seja obtida uma proteína de melhor qualidade.
Assim, uma menor ingestão de cereais (ricos em aminoácidos sulfurados) será necessária e dietas menos calóricas poderão ser formuladas, pois o feijão apresenta baixo teor de gordura e de sódio e não contém colesterol (HOSFIELD, 1991; MORROW, 1991).

Para tanto, é preciso avaliar se é possível aumentar o teor de cisteína por meio de melhoramento clássico, pois não há registros na literatura sobre isso. Além disso, também é preciso avaliar se ocorre alteração na composição dos aminoácidos essenciais e nãoessenciais quando se modifica o teor de cisteína em feijão, pois o incremento de um aminoácido não pode comprometer a disponibilidade de outro aminoácido, sob o risco de comprometer a qualidade dessa proteína.

Assim, os objetivos deste trabalho foram avaliar a composição de aminoácidos em gerações precoces de feijão, obtidas a partir de cruzamentos controlados com genitor de alto teor de cisteína, e selecionar plantas $\mathrm{F}_{2}$ para o desenvolvimento de populações segregantes de feijão com alto teor de cisteína nos grãos.

\section{MATERIAL E MÉTODOS}

Dois genitores contrastantes para o teor de cisteína (1. TPS Nobre: 0,95g por $16 \mathrm{~g} N$ e 2. Minuano: $1,43 \mathrm{~g}$ por $16 \mathrm{~g} \mathrm{~N}$ ) foram selecionados a partir dos resultados obtidos por RIBEIRO et al. (2007). As duas cultivares são do grupo comercial preto, sendo que a 'TPS Nobre' apresenta hábito de crescimento indeterminado com guias curtas (tipo II) e a 'Minuano' possui guias longas (tipo III).

Os cruzamentos controlados foram realizados em casa-de-vegetação do Departamento de Fitotecnia, da Universidade Federal de Santa Maria (UFSM), Rio Grande do Sul (RS), em 2006. No período de outono/inverno de 2006, foram obtidas as sementes F1 $\left(1+\right.$ x $\left.20^{\wedge}\right)$ e F1 recíproco $\left(2 \circ\right.$ x $\left.10^{\lambda}\right)$. Estas foram semeadas entre a primavera e o verão de 2006 para a obtenção das sementes $\mathrm{F}_{2}$ (autofecundação das plantas $\mathrm{F}_{1}$ ), $\mathrm{F}_{2}$ recíproco (autofecundação das plantas $\mathrm{F}_{1}$ recíproco), retrocruzamento 1 ( $\left.\mathrm{RCP}_{1}: \mathrm{F}_{1} \times 1\right)$ e retrocruzamento $2\left(\mathrm{RCP}_{2}: \mathrm{F}_{1} \times 2\right)$. Sementes $\mathrm{F}_{1}$ e $\mathrm{F}_{1}$ recíproco foram novamente obtidas, na segunda época, para possibilitar a avaliação de sementes desenvolvidas sob as mesmas condições de ambiente e com a mesma idade. Em cada etapa foram consideradas, no mínimo, 10 plantas de cada genitor e das gerações $F_{1}, F_{1}$ recíproco, $\mathrm{RCP}_{1}$ e $\mathrm{RCP}_{2}$ e 50 plantas das gerações $\mathrm{F}_{2} \mathrm{e}$ $\mathrm{F}_{2}$ recíproco. Os cruzamentos foram realizados com a emasculação do botão floral, utilizando a metodologia de entrelaçamento descrita em PETERNELLI \& BORÉM (1999). 
As plantas de feijão foram cultivadas em vasos plásticos, com capacidade para $5 \mathrm{l}$ da mistura solo + substrato comercial Plantimax ${ }^{\circledR}+$ casca de arroz carbonizada, na proporção volumétrica de 2:1:1. O solo utilizado foi o Alissolo Hipocrômico argilúvico típico, com a seguinte composição química: $\mathrm{pH}\left(\mathrm{H}_{2} 0\right)$ : 5,5, matéria orgânica: 2,2\%, fósforo: $6,8 \mathrm{mg} \mathrm{dm}^{-3}$, potássio: $68 \mathrm{mg} \mathrm{dm}^{-3}$, cálcio: $5,5 \mathrm{cmol} \mathrm{dm}^{-3}$ e magnésio: $2,7 \mathrm{cmol}_{\mathrm{c}}$ $\mathrm{dm}^{-3}$. A correção da fertilidade do solo foi realizada para os minerais considerados limitantes no solo.

Foram realizadas irrigações diárias para garantir o desenvolvimento normal das plantas de feijão e a integridade dos botões florais. O controle de insetos e de doenças foi efetuado sempre que necessário. Foi realizada a colheita de forma individualizada à medida que as vagens de feijão atingiram a maturação,. Os grãos foram secados em estufa $\left(65\right.$ a $\left.70^{\circ} \mathrm{C}\right)$ até umidade média de $13 \%$, quando foram moídos em micromoinho até a obtenção de partículas inferiores a $1 \mathrm{~mm}$. As amostras foram armazenadas em embalagens plásticas, devidamente identificadas, e conservadas sob refrigeração até a realização das análises.

A determinação dos teores de aminoácidos foi realizada no Laboratório de Análises Micotoxicológicas (LAMIC) da UFSM, Santa Maria, RS, por cromatografia líquida de alta performance (HPLC). As amostras passaram por hidrolização prévia com ácido clorídrico ( $\mathrm{HCl}$ ) bidestilado $6 \mathrm{~N}$, seguida de derivação pré-coluna dos aminoácidos livres com fenilisotiocianato (PITC) e da separação dos derivativos feniltiocarbamil-aminoácidos (PTC-aa) em coluna de fase reversa C18 (Pico-Tag - 3,9x300mm), com detecção por UV a 254nm. A quantificação da amostra foi baseada na altura de cada pico de aminoácido, sendo usada como referência a altura do pico do padrão interno de aminoácidos com concentração conhecida, com o padrão derivado nas mesmas condições e no mesmo tempo que as amostras. Os teores de aminoácidos foram transformados para gramas por $16 \mathrm{~g} \mathrm{~N}$ de amostra seca. Para isso, o teor de proteína bruta (PB, g por $100 \mathrm{~g}$ matéria seca - MS) da amostra foi determinado pelo método de micro-Kjeldahl (N x 6,25), a partir da metodologia descrita pela ASSOCIATION OF OFFICIAL AGRICULTURAL CHEMISTS (1995).

As análises estatísticas foram realizadas com o auxílio do programa GENES (CRUZ, 2001), segundo o modelo inteiramente casualizado, com duas repetições para os genitores $\left(\mathrm{P}_{1}\right.$ e $\left.\mathrm{P}_{2}\right)$ e para as gerações $\mathrm{F}_{1}, \mathrm{~F}_{1}$ recíproco, $\mathrm{RCP}_{1}$ e $\mathrm{RCP}_{2}$ e quatro repetições para as gerações $F_{2}$ e $F_{2}$ recíproco. Cada repetição foi constituída por sementes obtidas de uma planta. Assim, para as gerações $\mathrm{F}_{2}$ e $\mathrm{F}_{2}$ recíproco, foram considerados os dados individuais de cada uma das quatro plantas (repetições) e para as demais gerações foram considerados os dados individuais de duas plantas (repetições). Todas as análises foram realizadas em duplicada, entretanto, em razão do alto custo das análises realizadas por HPLC, não foi possível quantificar os teores de aminoácidos em um número maior de repetições. Os dados obtidos foram submetidos à análise de variância, sendo utilizado o teste $\mathrm{F}$ a $5 \%$ de probabilidade de erro. As médias foram comparadas entre si pelo teste t a 5\% de significância.

A partir das médias e da matriz de variância e de covariância residual dos aminoácidos em que foram obtidas diferenças significativas entre os genitores e as gerações precoces (cisteína, prolina, tirosina, arginina, isoleucina e histidina), foi avaliada a dissimilaridade genética por meio de variáveis canônicas entre todos os tratamentos, conforme descrito em RAO (1952).

\section{RESULTADOS E DISCUSSÃO}

Diferenças significativas entre os genitores e as gerações precoces foram constatadas para os aminoácidos - cisteína, prolina, tirosina, arginina, isoleucina e histidina - e para o teor de proteína bruta (Tabela 1). Os teores de cisteína observados nas gerações precoces foram inferiores ao teor obtido na cultivar 'Minuano'. Assim, apesar da utilização de um genitor com alto teor de cisteína ('Minuano') nos cruzamentos controlados, não foi possível a obtenção de gerações precoces com alto teor de cisteína e, além disso, segregação transgressiva foi constatada. Como KELLY \& BLISS (1975) desenvolveram gerações precoces de feijão com alto teor de metionina nos grãos a partir de cruzamentos controlados com genitor de alto teor de metionina, acredita-se que o aumento do teor de cisteína por meio de melhoramento clássico tenha êxito. Entretanto, a partir do cruzamento entre 'TPS Nobre' $x$ 'Minuano' todas as gerações obtidas apresentaram baixo teor de cisteína nos grãos.

Como a cisteína é o aminoácido parcialmente essencial presente em menor quantidade no feijão (ABD EL-SAMEI \& LÁSZTITY, 1984; ANTUNES et al., 1995; RIBEIRO et al., 2007), é preciso averiguar se o somatório metionina + cisteína é superior a $1,7 \mathrm{~g}$ por $16 \mathrm{~g} \mathrm{~N}$ da $\mathrm{MS}$, pois este é o padrão adequado para suprir as necessidades diárias de um indivíduo adulto (FAO, 1998). Nesse sentido, apenas os genitores e as gerações $\mathrm{F}_{1}$ e $\mathrm{F}_{1}$ recíproco apresentaram teores de aminoácidos sulfurados (metionina + cisteína) adequados para uso na alimentação, de acordo com os critérios da FAO. As demais gerações apresentaram deficiência em aminoácidos sulfurados. 
Tabela 1 - Composição de aminoácidos não-essenciais e essenciais (em gramas por 16g de N da matéria seca) e de proteína bruta (em gramas por $100 \mathrm{~g}$ de matéria seca) de grãos de feijão dos genitores e gerações obtidas a partir do cruzamento entre 'TPS Nobre’ x 'Minuano'. Santa Maria - RS, UFSM, 2007.

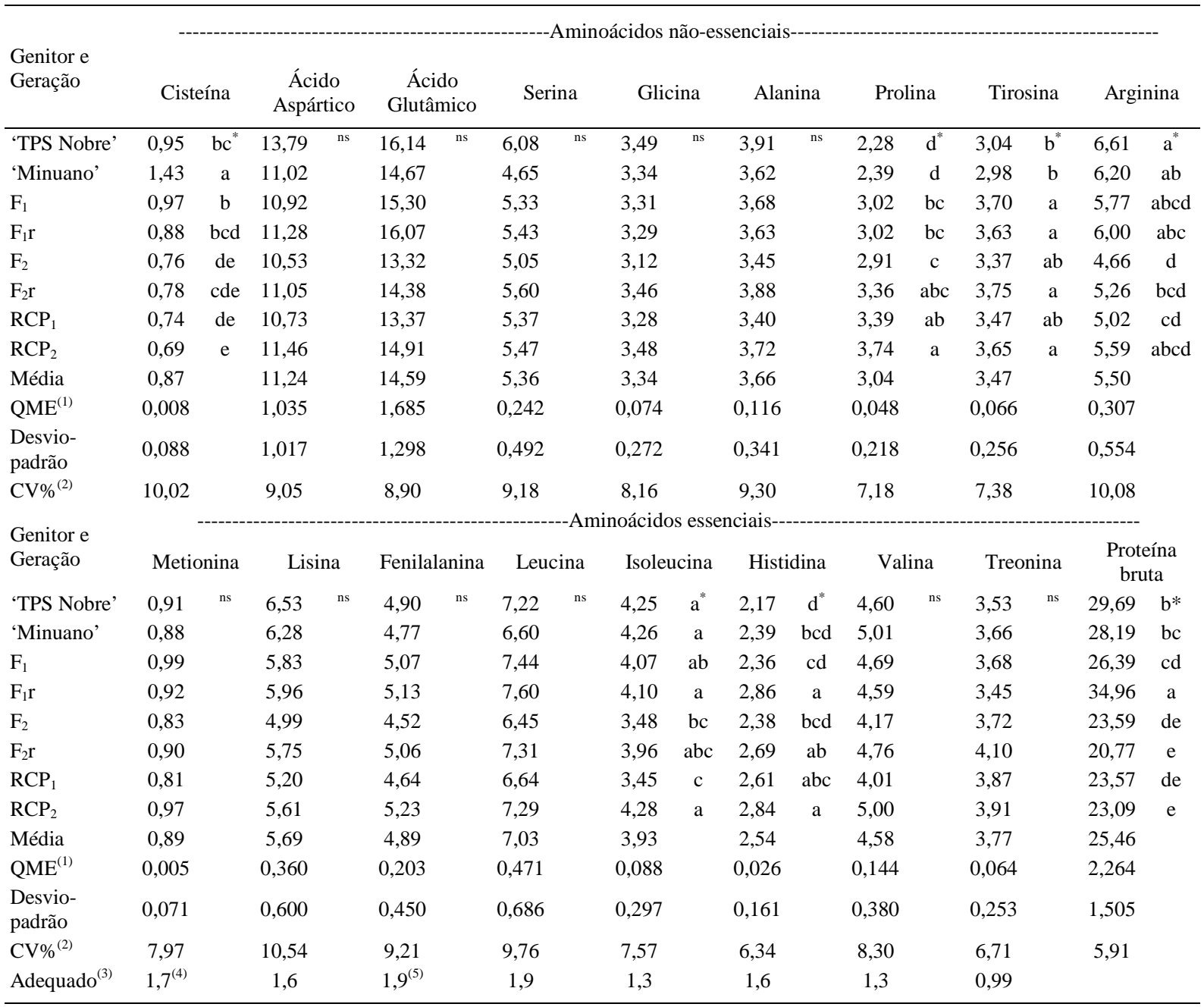

*Médias não seguidas de mesma letra, na vertical, diferem a 5\% de probabilidade de erro pelo teste t. ${ }^{\text {ns. }}$ : não-significativo. ${ }^{(1)}$ QME: Quadrado médio do erro. ${ }^{(2)} \mathrm{CV} \%$ : Coeficiente de variação experimental. ${ }^{(3)}$ Valor considerado adequado pela FAO (1998) para suprir as necessidades diárias de um indivíduo adulto. ${ }^{(4)}$ Metionina + cisteína. ${ }^{(5)}$ Fenilalanina + tirosina.

Os teores de prolina obtidos nas gerações precoces foram superiores aos verificados nos genitores 'TPS Nobre' e 'Minuano', provavelmente, em razão dos efeitos de dominância e/ou da sobredominância na expressão do teor de prolina em feijão. Assim, acréscimos no teor de prolina foram constatados em gerações precoces de feijão com baixo teor de cisteína. Entretanto, como o feijão é uma planta autógama, se espera que a heterose seja reduzida pela metade em cada geração de autofecundação e, por isso, a geração $\mathrm{F}_{3}$ poderá apresentar média inferior à geração $\mathrm{F}_{2}$ devido ao aumento da homozigose. Por isso, a avaliação em gerações avançadas se faz necessária para se investigar como será a segregação para esse caráter.

Com relação à tirosina, também foram observados incrementos nas gerações precoces, quando comparadas aos genitores utilizados nos cruzamentos controlados, indicando efeito de dominância e/ou sobredominância para o teor de tirosina em feijão e, por isso, não se espera que ocorra a fixação de um teor de tirosina elevado em gerações mais avançadas. No entanto, os valores obtidos nas gerações $\mathrm{F}_{2}$ e RCP 1 não apresentaram significância em relação aos teores das cultivares 'TPS Nobre' e 'Minuano'. Desse modo, pode-se constatar que o teor

Ciência Rural, v.39, n.2, mar-abr, 2009. 
de tirosina em feijão pode ser aumentado ou mantido por meio de melhoramento clássico. Por sua vez, o teor de arginina se reduz ou se mantém nas gerações precoces de feijão que apresentaram baixo teor de cisteína. Nesse caso, se verificou que os valores obtidos nas gerações $\mathrm{F}_{2}$ e RCP $\mathrm{R}_{1}$ foram inferiores aos teores registrados nos genitores; nas demais gerações, valores similares foram observados.

Com relação aos aminoácidos essenciais, diferenças significativas entre as gerações foram constatadas apenas para os teores de isoleucina e de histidina (Tabela 1). Para a isoleucina, foi observado que os teores obtidos nas gerações precoces foram similares aos valores dos genitores, exceto para as gerações $\mathrm{F}_{2}$ e $\mathrm{RCP}_{1}$, pois os valores obtidos foram inferiores. Como os genitores utilizados apresentaram pouca variabilidade genética para o teor de isoleucina, a amplitude verificada foi pequena e segregação transgressiva foi constatada nas gerações $\mathrm{F}_{2}$ e RCP . Para a histidina, constatou-se que as gerações $\mathrm{F}_{1} \mathrm{r}$ e $\mathrm{RCP}_{2}$ apresentaram os maiores valores. Vale ressaltar que os teores de isoleucina e de histidina foram superiores ao padrão estabelecido pela FAO (1998), mesmo naquelas gerações em que o teste t classificou como baixo teor.

A partir do cruzamento entre 'TPS Nobre' $\mathrm{x}$ 'Minuano' foram obtidas gerações precoces com teores de aminoácidos essenciais e não-essenciais semelhantes aos valores observados em algumas cultivares de feijão disponíveis para o cultivo no Brasil (RIBEIRO et al., 2007). Assim, por meio de melhoramento clássico, é possível desenvolver germoplasma de feijão com melhor qualidade de proteína, pois nem todas as cultivares de feijão apresentam quantidades adequadas de aminoácidos para uso na alimentação. Além disso, os teores de lisina, fenilalanina, leucina, isoleucina, histidina, valina e treonina observados, nas diferentes gerações, foram superiores ao teor padrão considerado adequado pela FAO para suprir as necessidades diárias de um indivíduo adulto (FAO, 1998).

Entretanto, os teores de aminoácidos sulfurados (metionina + cisteína) somente foram considerados adequados para uso na alimentação (FAO, 1998), nos genitores ('TPS Nobre’ e 'Minuano') e nas gerações $F_{1}$ e $F_{1}$ recíproco. Assim, apenas os genitores e as gerações $F_{1}$ e $F_{1}$ recíproco não apresentaram limitação em nenhum dos aminoácidos essenciais, conferindo alta qualidade à proteína do feijão. As demais gerações apresentaram pequena quantidade de metionina e de cisteína e, por isso, foram de baixo valor nutritivo, de acordo com a definição de MOLINA et al. (2001).
Para as avaliações das variáveis canônicas, foram considerados os seis aminoácidos em que foram verificadas diferenças significativas na análise da variância (Tabela 1). Considerando que cada variável canônica é uma combinação linear das variáveis originais analisadas, observou-se que as duas primeiras variáveis canônicas explicaram 96,43\% da variação observada entre genótipos (Tabela 2). Assim, 88,51\% das diferenças entre os genitores e as gerações obtidas referem-se à primeira variável canônica e 7,92\%, à segunda variável canônica.

Nesse caso, foi possível a visualização gráfica bidimensional do germoplasma avaliado, utilizando a primeira e a segunda variável canônica (Figura 1). Dois grupos foram formados com os escores das variáveis canônicas. O grupo 1 foi formado pelos genitores ('TPS Nobre' e 'Minuano’) que diferenciaramse pelos elevados teores de cisteína e de arginina e pelos baixos teores de prolina, tirosina e histidina (Tabela 3). O grupo 2 foi constituído pelas demais gerações obtidas. As principais características observadas neste grupo foram a manutenção do teor de isoleucina, os baixos teores de cisteína e de arginina e os maiores valores de prolina, tirosina e histidina. Como segregação transgressiva foi constatada para o teor de cisteína, todas as gerações obtidas apresentaram baixo teor de cisteína e, por isso, diferiram significativamente dos genitores, sendo agrupadas em um grupo com teores de aminoácidos tão diferenciados dos teores observados nos genitores.

Como o consumo de feijão faz parte do hábito alimentar de uma parcela significativa da população brasileira e algumas cultivares utilizadas rotineiramente na alimentação apresentaram teores de aminoácidos sulfurados adequados para satisfazer os requerimentos nutricionais diários (RIBEIRO et al., 2007), a disponibilização de cultivares com melhor qualidade

Tabela 2 - Variâncias, variâncias percentuais e acumuladas das variáveis canônicas obtidas de seis aminoácidos avaliados a partir do cruzamento entre 'TPS Nobre' $\mathrm{x}$ 'Minuano' e nas seis gerações desenvolvidas a partir desse cruzamento. Santa Maria - RS, UFSM, 2007.

\begin{tabular}{lccc}
\hline Variáveis & ----------------Variância----------------- \\
canônicas & $\begin{array}{c}\text { Variável } \\
\text { canônica }\end{array}$ & Percentual & $\begin{array}{c}\text { Percentual } \\
\text { acumulado }\end{array}$ \\
\hline 1 & 0,0258734 & 88,51 & 88,51 \\
2 & 0,1499211 & 7,92 & 96,43 \\
3 & 0,0256032 & 2,04 & 98,47 \\
4 & 0,0155522 & 0,87 & 99,34 \\
5 & 0,0029502 & 0,46 & 99,80 \\
6 & 0,0030756 & 0,20 & 100,00 \\
\hline
\end{tabular}




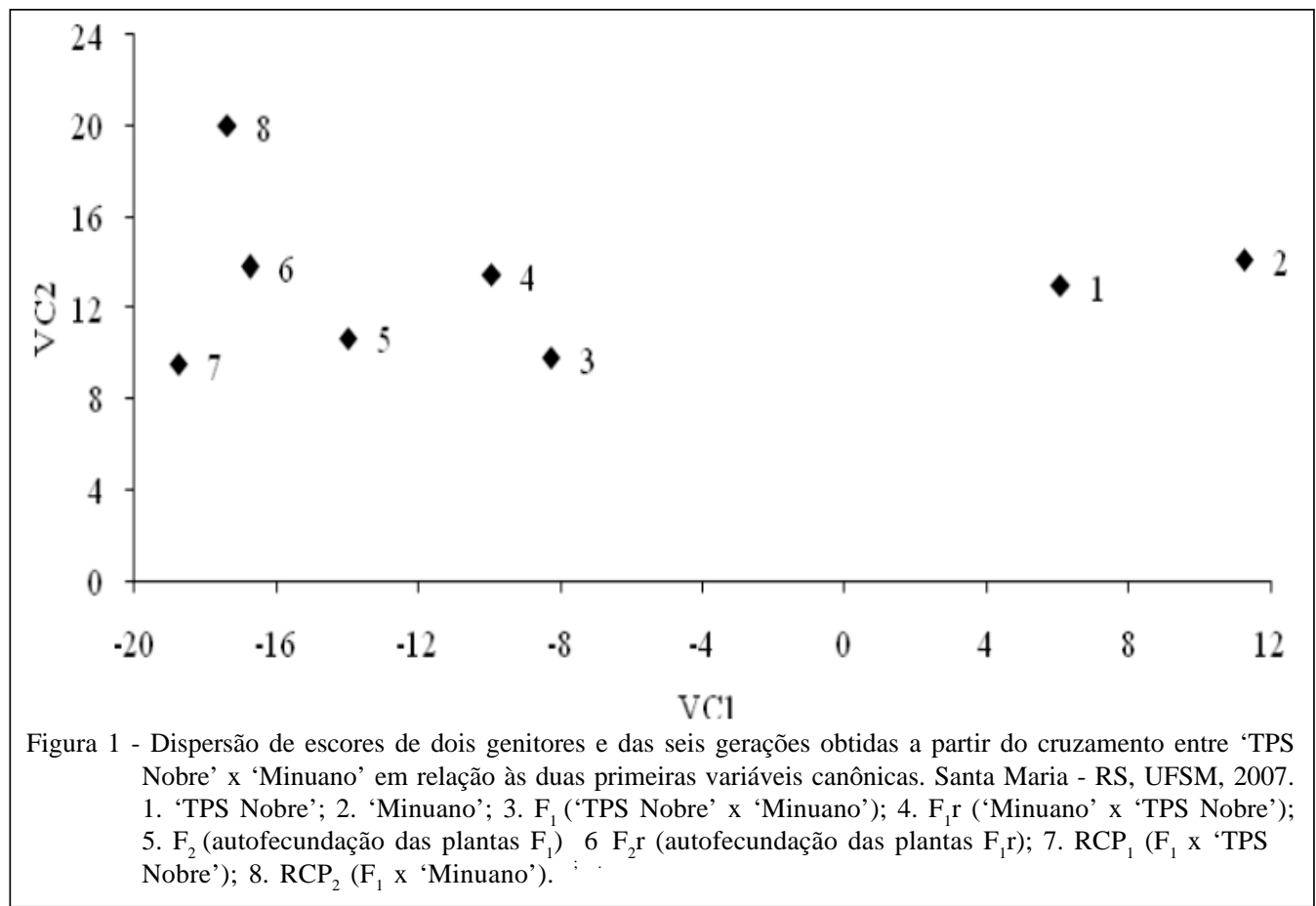

de proteína terá um grande benefício social, principalmente nas classes de menor poder aquisitivo. Isso porque vários efeitos benéficos ao organismo têm sido relacionados aos teores de aminoácidos (COSTA, 2003) e isso terá implicação direta na manutenção do estado de saúde e na prevenção de várias doenças. Por isso, é importante o aumento dos teores de aminoácidos sulfurados em feijão e a busca constante de alternativas para se atingir essa meta.

Considerando os valores individuais das plantas com grãos da geração $\mathrm{F}_{2}$ nenhuma planta será selecionada pelo programa de melhoramento devido aos baixos teores de metionina + cisteína nos grãos de feijão. Isso porque os grãos da geração $F_{2}$ foram deficientes em aminoácidos sulfurados, de acordo com o padrão adotado pela FAO (1998). Assim, outras combinações híbridas deverão ser testadas para observar se é possível aumentar o teor de cisteína em feijão. Como KELLY \& BLISS (1975) conseguiram obter gerações precoces de feijão com alto teor de metionina, a partir de cruzamentos controlados com genitor de alto teor de metionina, talvez a estratégia de aumentar o teor de aminoácidos sulfurados, via aumento do teor de metionina nos grãos, seja a mais indicada. Assim, a partir do cruzamento entre 'TPS Nobre' $\mathrm{x}$ 'Minuano' não foi possível obter gerações precoces com alto teor

Tabela 3 - Teores médios de aminoácidos (em gramas por 16g de N da matéria seca) dos dois grupos formados a partir do cruzamento entre 'TPS Nobre' x 'Minuano', com base na matriz das distâncias de Mahalanobis, utilizando variáveis canônicas. Santa Maria - RS, UFSM, 2007.

\begin{tabular}{|c|c|c|c|c|c|c|}
\hline Grupo $^{1}$ & Cisteína & Prolina & Tirosina & Arginina & Isoleucina & Histidina \\
\hline 1 & $1,19 a$ & $2,34 b$ & $3,01 b$ & $6,41 a$ & $4,26 a$ & $2,28 b$ \\
\hline 2 & $0,80 \mathrm{~b}$ & $3,21 a$ & $3,59 a$ & $5,28 b$ & $3,85 a$ & $2,60 \mathrm{a}$ \\
\hline Média geral & 0,87 & 3,04 & 3,47 & 5,50 & 3,93 & 2,54 \\
\hline $\mathrm{QME}^{(2)}$ & 0,0240 & 0,0995 & 0,0638 & 0,4020 & 0,1436 & 0,0527 \\
\hline Desvio padrão & 0,1549 & 0,3155 & 0,2525 & 0,6341 & 0,3789 & 0,2295 \\
\hline $\mathrm{CV} \%^{(3)}$ & 17,71 & 10,38 & 7,27 & 11,52 & 9,64 & 9,04 \\
\hline
\end{tabular}

*Médias não seguidas de mesma letra, na vertical, diferem a $5 \%$ de probabilidade de erro pelo teste $t .{ }^{\text {ns. }}$ : não-significativo.

${ }^{1}$ Grupo: 1: ‘TPS Nobre’ e 'Minuano’; 2: demais gerações segregantes. ${ }^{(2)}$ QME: Quadrado médio do erro. ${ }^{(3)} \mathrm{CV} \%$ : Coeficiente de variação experimental.

Ciência Rural, v.39, n.2, mar-abr, 2009. 
de cisteína nos grãos, indicando dificuldades para aumentar esse aminoácido sulfurado por meio do melhoramento clássico.

\section{CONCLUSÕES}

As cultivares ‘TPS Nobre' e 'Minuano' e as gerações $\mathrm{F}_{1}$ e $\mathrm{F}_{1}$ recíproco apresentam quantidade de aminoácidos essenciais e não-essenciais adequada para uso na alimentação humana. Nenhuma planta da geração $F_{2}$ é passível de seleção pelo programa de melhoramento para o desenvolvimento de populações segregantes de feijão com alto teor de cisteína nos grãos.

\section{AGRADECIMENTOS}

Ao Conselho Nacional de Desenvolvimento Científico e Tecnológico (CNPq), pelo aporte financeiro e pelas bolsas concedidas. À Coordenação de Aperfeiçoamento de Pessoal de Nível Superior (CAPES), pela bolsa de doutorado.

\section{REFERÊNCIAS}

ABD EL-SAMEI, M.H.; LÁSZTITY, R. Comparative study on the amino acids composition in three local Phaseolus vulgaris seeds varieties. Zeitschrift für Lebensmitteluntersuchung und - Forschung A, Heidelberg, v.178, n.1, p.24-26, 1984.

ANTUNES, P.L. et al. Valor nutricional de feijão (Phaseolus vulgaris, L.), cultivares 'Rico 23', 'Carioca', 'Piratã-1' e 'Rosinha-G2'. Revista Brasileira de Agrociência, Pelotas, v.1, n.1, p.12-18, 1995.

ASSOCIATION OF OFFICIAL AGRICULTURAL CHEMISTS. Official methods of analysis. 16.ed. Washington, DC, 1995. 2000p.

COSTA, N.M.B. Alimentos: componentes nutricionais e funcionais. In: COSTA, N.M.B; BORÉM, A. Biotecnologia e nutrição: saiba como o DNA pode enriquecer os alimentos. São Paulo: Nobel, 2003. Cap.2, p.31-69.

CRUZ, C.D. Programa GENES: versão Windows, aplicativo computacional em genética e melhoramento. Viçosa: UFV, 2001. 648p.
FAO. Junta de Conselho de Especialistas FAO/WHO/ONU. Necessidades de energia e proteína. São Paulo: Roca, 1998. 225p.

FONSECA MARQUES, M.F.; BORA, P.S. Composición química y análisis de aminoácidos de alubias. Ciencia y Tecnología Alimentaria, Reynosa, v.2, n.5, p.248-252, 2000.

GUZMÁN-MALDONADO, S.H. et al. Protein and mineral content of a novel collection of wild and weedy common bean (Phaseolus vulgaris L). Journal of the Science of Food and Agriculture, London, v.80, n.13, p.1874-1881, 2000.

HOSFIELD, G.L. Genetic control of production and food quality factors in dry bean. Food Technology, Chicago, v.45, n.9, p.98-103, 1991.

KELLY, J.D.; BLISS, F.A. Heritability estimates of percentage seed protein and available methionine and correlations with yield in dry beans. Crop Science, Madison, v.15, n.6, p.753757, 1975.

LAJOLO, F.M.; TIRAPEGUI, J. Proteínas e aminoácidos. In: DUTRA-DE-OLIVEIRA, J.E.; MARCHINI, J.S. Ciências nutricionais. São Paulo: Sarvier, 1998. Cap.3, p.41-69.

MOLINA, S.M.G. et al. Manipulação de cereais para acúmulo de lisina nas sementes. Scientia Agrícola, Piracicaba, v.58, n.1, p.205-211, 2001.

MORALES DE LEON, J. et al. Amino acid composition of some mexican foods composición de aminoácidos en varios alimentos mexicanos. Archivos Latinoamericanos de Nutrición, Caracas, v.55, n.2, p.172-186, 2005.

MORROW, B. The rebirth of legumes. Food Technology, Chicago, v.45, n.9, p.96- 121, 1991.

PETERNELLI, L.A.; BORÉM, A. Hibridação em feijão. In: BORÉM, A. Hibridação artificial de plantas. Viçosa: UFV, 1999. p.269-294.

PIRES, C.V. et al. Qualidade nutricional e escore químico de aminoácidos de diferentes fontes protéicas. Ciência e Tecnologia dos Alimentos, Campinas, v.26, n.1, p.179-187, 2006.

RAO, R.C. Advanced statistical methods in biometric research. New York: John Wiley, 1952. 390p.

RIBEIRO, N.D. et al. Composição de aminoácidos de cultivares de feijão e aplicações para o melhoramento genético. Pesquisa Agropecuária Brasileira, Brasília, v.42, n.10, p.1393-1399, 2007. 